\title{
The impact of ethical climate on turnover intentions and organizational performance
}

\author{
Zahra Nikkhah Farkhani $^{a^{*}}$, Zeinab Armoun ${ }^{b}$ and Mojtaba Javidnia ${ }^{c}$
}

${ }^{a}$ Faculty Member at the College of Mashhad, Ferdowsi University of Mashhad, Mashhad, Iran

${ }^{b}$ Master of Science, Mashhad Ferdowsi, faculty of Administrative Sciences \& Economic, Department of management

${ }^{c}$ Department Of Management, Young Researchers Club, Semnan Branch, Islamic Azad University, Semnan, Iran

\section{H R O N I C L E A B S T R A C T}

Article history:

Received January 12, 2013

Received in revised format 30 April 2013

Accepted 12 May 2013

Available online

May 142013

Keywords:

Ethical climate

Turnover intentions

Organizational performance

Data envelopment analysis

\begin{abstract}
This paper investigates the impact of ethical climate on turnover intentions and organizational performance based on the implementation of various techniques. The interview method was used to identify the factors of input and output. Required data were collected to measure performance of firms based on some documents. The survey method was used to study the ethical climate and turnover intentions. The impact of ethical climate on turnover intentions and organizational performance was evaluated. The information was analyzed based on different software packages including Deap2.1, SPSS.18 (PASW) and Lisrel 8.1. The preliminary results indicate that organizational ethical climate positively impacts on sales representative performance and negatively influences on turnover Intentions. The highest positively correlations were between sales practices and organizational performance $(\mathrm{r}=0.48)$ and the highest negatively correlations were between sales practices and turnover intentions $(\mathrm{r}=-0.72)$.
\end{abstract}

(C) 2013 Growing Science Ltd. All rights reserved.

\section{Introduction}

Today, the increasing complexity of organizations and the rising rate of immoral and illegal actions in work environments have made it necessary for the managers and the heads of organizations to create and to maintain a moral working environment. Organizational moral environment is an indicator of moral values, behavioral expectations, and the effect of moralities on the decisions made by an organization's members, and means that there were moral choices when we recruit staffs and measure their performances. Studies in this field have demonstrated that there was a relationship between direct observation of an observer and intention towards immoral behavior in organizations. Therefore, those sellers and marketers who are not under any direct observation are more likely to behave immorally (Kazimi et al., 2008). For instance, sales representatives are the best people who could reflect organizational moralities.

*Corresponding author. Tel: +989156511743

E-mail addresses: nikkhah.hrm@gmail.com (Z. Nikkhah Farkhani) 
According to numerous researches in this field, moral values and organizational moral environment influence organizational commitment (Sarmad et al., 2006), role conflict (Coninck, 2011), job satisfaction, job quitting, and organizational performance (Schwepker, 2001) are important areas of research. This research aims to study the effects of organizational moral environment on organizational performance and quitting intention of the sellers of an active company in food production industry.

\section{Organizational performance}

Organizational performance is a general concept, which refers to different method that organizational operations are carried out. Researchers have implemented various techniques based on several criteria such as efficiency, quality, profitability, and productivity to measure organizational performance (Ramanathan, 2007). Efficiency, which is the results of the best utilization of resources many represent for different purposes. Efficiency is an indicator of the ratio of outputs to inputs compared with some standards (Bellizzi \& Hasty, 2003). Measuring the relative efficiency of organizations has attracted many people for the past few years. Charles et al. (1978) is believed to be the first who introduced the idea of data envelopment analysis for measuring the relative efficiency of similar units. During the past few years, DEA has been used to assess the performance of service units such as banks, educational units, and travel agencies, and to analyze the performance of provision chains (Mulki \& Locander, 2006), manufacturing industries (Adams, 2008), agricultural industries (Posner \& Schmidt, 1993), insurance industry (Wong \& Wong, 2007), and many other services and industries. DEA has 2 major advantages in respect to performance measuring. First, in this method, there is no need to specify a function concerning the inputs and outputs, meaning that a researcher could avoid the limitations of choosing the form of production or cost functions, which could influence the results of performance analysis (Ertay \& Tuzkaya, 2006). Second, this method does not need any statistical distribution assumptions for performance elements. Therefore, although in most similar researches, researchers have considered profitability as the only criterion of organizational performance, in this research, DEA was used to measure the performance of sales agencies, and to apply a systemic perspective. These agencies were studied based on their relative efficiency and organizational performance.

\section{Research Hypotheses}

Research hypotheses were developed according to the research goals and literature as below:

Major Hypothesis 1: There is a significant and negative relationship between the organizational moral environment and the quitting intentions among employees.

Hypothesis 1-A: There is a significant and negative relationship between the moral norms and the quitting intentions of the employees.

Hypothesis 1-B: There is a significant and negative relationship between the moral responsibility/trust of the employees and their quitting intentions.

Hypothesis 1-C: There is a significant and negative relationship between the moral behavior of the employees and their quitting intentions.

Hypothesis 1-D: There is a significant and negative relationship between the moral actions associated with sales and the quitting intentions of the employees.

Hypothesis 2: There is a significant positive relationship between the organizational moral environment and the performance levels of the sales agencies. 
Hypothesis 2-A: There is a significant positive relationship between the moral norms and the performance levels of the sales agencies.

Hypothesis 2-B: There is a significant positive relationship between the moral responsibility/trust of the employees and the performance levels of the sales agencies.

Hypothesis 2-C: There is a significant positive relationship between the moral behavior of the employees and the performance levels of the sales agencies.

Hypothesis 2-D: There is a significant positive relationship between the moral actions related to sales and the performance levels of the sales agencies.

Hypothesis 3: There is a significant negative relationship between the performance levels of the sales agencies and the quitting intentions of the employees.

\section{Methodology}

The nature of research studies could be exploratory or descriptive. While exploratory researches aim to make it easier to understand an issue's nature that little research may have been done on its related phenomena, descriptive researches are carried out to determine and describe the characteristics of the variables in a given situation (Mokhtar \& Alhabshi, 2008). Descriptive researches are divided into subcategories of survey researches, correlation researches, action researches, case studies, and causalcomparative researches. Survey researches are applied when reviewing the distribution of the attributes of a statistical population (Yao et al., 2007). The current research has three stages. In the first stage, exploratory methods have been used and senior and informed managers of the organization have been interviewed to identify the input and output factors, which influence the organizational performance. Variance Inflation Factor (VIF) was implemented to make sure of the effects of the above-mentioned factors on the organizational performance, and a tolerable multicollinearity among input factors. VIF is calculated through the following equation:

$V I F_{i}=\frac{1}{1-R_{i}^{2}}$

If VIF assumes a value higher than 100, it will be the indication of (combined coefficient of determination) value being very high and that the $i^{\text {th }}$ variable could be calculated through the linear combination of other variables, meaning that there is no need for the $i^{\text {th }}$ factor to be present among the input factors. In general, a value of VIF between 10 and 100 is tolerable, while VIF values lower than 10 are more appropriate for showing the independence of a variable from other variables or a factor from other factors (Coeli, 1998). The results of this stage are presented in Table 4. In the second stage, after using document analysis methods to determine the factors influencing the performance of the sales agencies, data was collected and analyzed using DEA, and the efficiency of each of the sales agencies was calculated. Descriptive-survey methods were used in the third stage where organizational moral environment and quitting intentions questionnaires were handed out to marketers, and the effects of organizational moral environment on organizational performance and quitting intentions of employees was studied. The statistical population of the current research was all the 250 sellers and marketers employed in 59 sales agencies of the organization under study in all the provinces of Iran. Since the current research aimed to study all the sales agencies and the number of sellers was not the same in these agencies, data was collected through stratified sampling, and the sample size was determined using optimum allocation method and the Morgan Table for 127 individuals. In order to test and measure the organizational moral environment, the questionnaire developed by Mr. Babin for the same purpose, covering the four aspects of moral responsibility/trust of employees, moral behavior of employees, moral norms, and moral actions related to sales, was used, while the quitting intentions of employees were measured using Deconinck and Stillwell 3-item 
questionnaire. Cronbach's Alpha Coefficient was used to measure the reliability of the questionnaires, and calculated for organizational moral environment and quitting intentions questionnaires as to be equal to 0.85 and 0.82 , respectively. This means that both questionnaires had decent reliabilities. Although the validity of organizational moral environment and quitting intentions (Jawahar \& Hemmasi, 2006) questionnaires has been confirmed in former researches, content validity and construct validity (confirmatory factor analysis) methods have been used in this research to remeasure the validity of the questionnaires. In order to measure the content validity of organizational moral environment and quitting intentions questionnaires, they were presented to a number of experts in this field, while the construct validity of the questionnaires was measured using structural equation modeling. The validity and reliability of the questionnaires were confirmed based on the agreeable level of the metrics of the model's goodness of fit: (RMSEA $=0.021, \mathrm{GFI}=0.92$, AGFI $=0.94, \chi^{2} / \mathrm{df}=2.63$ ).

\section{Research Findings}

The factors influencing the performance of the sales agencies were identified by interviewing the experts in the organization under study, while the multi-collinearity rate of these factors was measured using Principal Component Analysis (PCA). The results are shown in Table 1.

\section{Table 1}

Input and output factors for measuring organizational performance

\begin{tabular}{clcccc}
\hline Factor Type & \multicolumn{1}{c}{ Factors } & Avg. & Max. & Min. & VIF \\
\hline \multirow{5}{*}{ Input } & The work experience of the sales agency's manager (in years) & 9.5 & 14 & 1.5 & 0.1 \\
& The number of marketers & 3 & 11 & 1 & 14.28 \\
& Marketer's work experience (in years) & 2 & 7 & 0.5 & 1.06 \\
& Marketers' monthly salary (in thousand Tomans) & 310 & 520 & 150 & 4.78 \\
& Capital (in million Tomans) & 24.23 & 50 & 8 & 6.49 \\
& Machinery usage rate & 4 & 13 & 2 & 14.28 \\
& Transportation costs (in million Tomans) & 23.86 & 41 & 13 & 11.11 \\
& Water, power, and gas consumption costs (in million Tomans) & 1.22 & 3 & 0.1 & 8.33 \\
& Fuel costs & 1.54 & 2.5 & 0.14 & 1.12 \\
\hline & Net profitability rate (output) & 9.11 & 16 & 1 & - \\
\hline
\end{tabular}

In order to test the research hypotheses, the performance of the sales agencies were calculated with respect to the above-mentioned factors and each other using DEA and Deap 1.2. The results have indicated that in total, 18 agencies had acted optimally and could make use of all their facilities to achieve a maximum performance, assuming that the ratio of productivity to scale was constant. The correlation between the variables of quitting intentions, organizational moral environment, and performance level was then calculated using SPSS 18 (PASW) and Pearson Correlation Test. Finally, the causal relationship between dependent and independent variables was calculated based on structuring equation modeling, path analysis, and Lisrel 8.51. Table 2 shows the results of Pearson Correlation Test for research variables where all the relations between these variables are significant at the confidence level of $95 \%$.

Table 2

Correlation coefficient of research variables

\begin{tabular}{lcc}
\hline & Pearson Correlation coefficient & t-value \\
\hline Performance levels of the sales agencies - organizational moral environment & 0.46 & 4.26 \\
Performance levels of the sales agencies - moral behavior of the employees & 0.34 & 6.18 \\
Performance levels of the sales agencies - moral actions related to sales & 0.51 & 3.58 \\
Performance levels of the sales agencies - moral norms & 0.42 & 8.42 \\
Performance levels of the sales agencies - moral responsibility/trust of the employees & 0.46 & 9.12 \\
Performance levels of the sales agencies - quitting intentions of the employees & -0.53 & 4.39 \\
Quitting intentions of the employees - organizational moral environment & -0.62 & 6.35 \\
Quitting intentions of the employees - moral behavior of the employees & -0.58 & 5.21 \\
Quitting intentions of the employees - moral actions related to sales & -0.49 & 4.62 \\
Quitting intentions of the employees - moral norms & -0.61 & 3.29 \\
Quitting intentions of the employees - moral responsibility/trust of the employees & -0.53 & 4.21 \\
\hline
\end{tabular}


As we can observe, organizational performance has the highest and lowest correlation with the moral actions associated with sales, and the moral behavior of the employees, respectively. In addition, from among organizational moral environment aspects, "moral norms" has the highest negative correlation with quitting intentions of sellers. Two models were used to test the research major and minor hypotheses. In the first model, the relationship between the four aspects of the organizational moral environment, quitting intentions and organizational performance was tested, and in the second model, the relationship between each organizational moral environment aspects, moral responsibility, employees' moral behavior, moral norms, and the moral actions related to sales, quitting intentions, and the organizational performance was examined. Fig. 1 and Fig. 2 show the results of both tests using path analysis, while Table 3 shows the overall results of testing the research hypotheses using the same method.

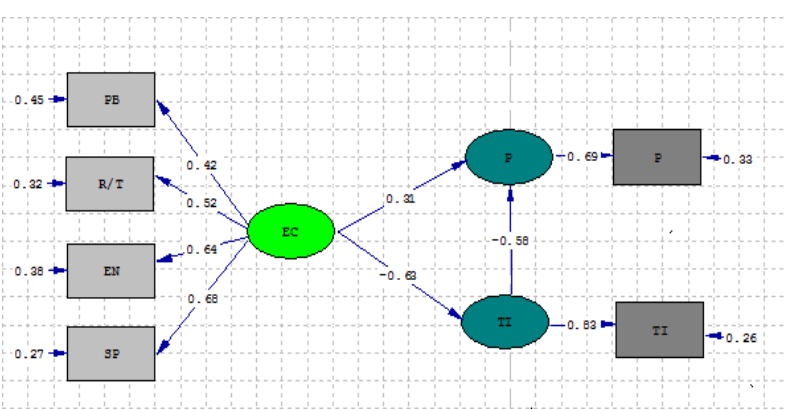

Fig. 1. The results of testing the major research hypotheses using the path analysis method

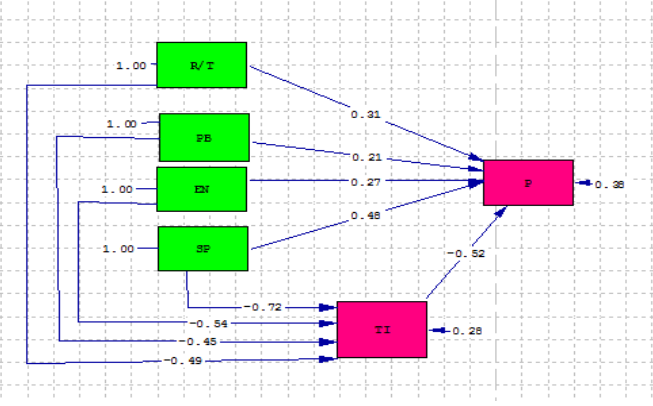

Fig. 2. The results of testing the minor research hypotheses using the path analysis method

According to Fig. 1, quitting intentions affected by organizational moral environment will affect, in turn, the performance of the sales agencies. Meanwhile, the effect of organizational moral environment on the lack of quitting intentions is more than its effect on the performance of the sales agencies. Fig. 2 shows the results of testing the research minor hypotheses using the path analysis method. According to the above figure, the effect of the moral actions related to sales with a standard coefficient of 0.48 on the performance of the agencies is more than the other aspects of the organizational moral environment. Also, "employees' quitting intentions" is more negatively affected by the moral actions related to sales than other aspects of the organizational moral environment. Table 3 shows a summary of the results of testing the research major and minor hypotheses and the metrics of each of the model's goodness of fit.

Table 3

The results of testing the research hypotheses using the path analysis method

\begin{tabular}{|c|c|c|c|c|}
\hline Model & hypotheses & $\mathrm{R}$ & t-value & Result \\
\hline \multirow{4}{*}{1} & organizational moral environment and the quitting intentions of the & -0.63 & 4.12 & Confirm \\
\hline & organizational moral environment and the performance levels of the & 0.31 & 3.59 & Confirm \\
\hline & quitting intentions of the employees and performance levels of the sales & -0.58 & 4.58 & Confirm \\
\hline & $\chi 2 / \mathrm{df}=2.31$ & $=0.82$ & $\mathrm{GFI}=0.91$ & RMSEA $=0.049$ \\
\hline \multirow{9}{*}{2} & moral norms and the quitting intentions of the employees & -0.54 & 3.43 & Confirm \\
\hline & moral actions related to sales and the quitting intentions of the & -0.72 & 3.42 & Confirm \\
\hline & moral behavior of the employees and their quitting intentions & -0.45 & 3.56 & Confirm \\
\hline & moral responsibility/trust of the employees and their quitting intentions & -0.49 & 3.69 & Confirm \\
\hline & moral norms and the performance levels of the sales agencies & 0.27 & 4.66 & Confirm \\
\hline & moral actions related to sales and the performance levels of the sales & 0.48 & 4.22 & Confirm \\
\hline & moral behavior of the employees and the performance levels of the sales & 0.21 & 3.41 & Confirm \\
\hline & moral responsibility/trust of the employees and the performance levels of & 0.31 & 3.29 & Confirm \\
\hline & performance levels of the sales agencies and the quitting intentions of the & -0.52 & 3.78 & Confirm \\
\hline
\end{tabular}


According to the results of Table 3 and the fact that all $\mathrm{t}$ values at the confidence level of $95 \%$ were significant, all the research hypotheses were confirmed. Besides, since in both models, the value of RMSEA was less than 0.05 , the ratio of Chi-square to freedom degree was less than 3 , the value of GFI was more than 0.09 , and the value of AGFI was more than 0.08 , the validity and goodness of fit of both models were also confirmed.

\section{Discussion and Conclusions}

According to the results of this research, the first hypothesis is confirmed, which means there is a negative and significant relationship between the organizational moral environment and quitting intentions with a path coefficient of 0.63 . In other words, if the employees of an organization know that there are moral procedures and policies in that organization, intentions to quit the organization will decrease among the sellers. In addition, from among the aspects of organizational moral environment, moral actions related to sales with a path coefficient of 0.72 had the biggest effect on the employees' quitting intentions. In other words, those sale agencies that assess the performance of their sellers and marketers only according to their daily or monthly sale rates, and don't think of customers' satisfaction of their services and the way such services are delivered, are more prone to losing their sellers and marketers than other agencies.

Moral norms established in an organization are another factor affecting the quitting intentions of sellers. The employees who consider their personal beliefs and values as contradictory to their organization's procedures and values are psychologically more inclined toward quitting. This finding has confirmed the results of former researches in the same field. A significant positive relation between organizational moral environment and organizational performance with a path coefficient of 0.31 stated by the second research hypothesis was also confirmed. In other words, organizational moral environment will lead to the equipment of organizations with global values that guarantee their decent performance and profitability. How organizational moral environment affects organizational performance has been studied from different perspectives in the researches done in the same field.

Some researchers state that organizational moral environment will lead to an increase in customer satisfaction and an organization's sales, so, it has a positive effect on organizational performance. Other researchers think a ruling organizational moral environment could affect the employees' satisfaction, and state that satisfied employees will ultimately do their best to improve their organizational performance. Yet, some other researchers think that in order for the organizational moral environment to have a positive effect on the performance, job stresses born in immoral environments and ill competitions in the work environments should be reduced. All aspects of organizational moral environment have positive and significant effect on the organizational performance of the sales agencies. Among these aspects, "moral actions by sellers" (moral actions related to sales) with a path coefficient of 0.48 has the biggest effect on the performance of the sales agencies.

The third hypothesis has also confirmed, which means that there was a negative and significant effect on quitting intentions on the organizational performance with a path coefficient of 0.58 . Reviewing quitting intentions and their realizations, many researchers have stated that although quitting has a bad effect on the organizational performance, those employees with quitting intentions who decide to remain in their organizations after analyzing the costs and benefits of realizing their intention, will have the worst influence on the organizational performance through inaction, creating tension among employees and exhibiting immoral behavior because they have no commitment to and selfidentification with organizational goals and ideals. 


\section{References}

Adams, D. S. (2008). Using data envelopment analysis to assess the technical efficiency of public school districts in Arkansas, a dissertation submitted to the graduate school university of Arkansas at little rock, for the degree of doctor of education.

Bellizzi, J., \& Hasty, R. (2003). Supervising unethical sales force behavior: how strong is the tendency to treat top sales performers leniently?. Journal of Businesses Ethics, 43, 337-351.

Charnes, A. C. T. C., Clark, C. T., Cooper, W. W., \& Golany, B. (1984). A developmental study of data envelopment analysis in measuring the efficiency of maintenance units in the US Air Forces. Annals of Operations Research,2(1), 95-112.

Coelli, T. J., Rao, D. P., O'Donnell, C. J., \& Battese, G. E. (2005). An introduction to efficiency and productivity analysis. Springer Science+ Business Media.

Ertay, T., Ruan, D., \& Tuzkaya, U. R. (2006). Integrating data envelopment analysis and analytic hierarchy for the facility layout design in manufacturing systems. Information Sciences, 176(3), 237-262.

Fishbein, M, \& Ajzen, I. (1975). Belief, attitude, intention and behavior: An introduction to theory and research. Reading MA: Addison-Wesley.

Heslin, P., \& VandeWalle, D. (2011). Performance appraisal procedural justice: The role of manager's implicit person theory. Journal of Management, 3, 1-25.

Jaros, S. J. (1997). An assessment of Meyer and Allen's (1991) three-component model of organizational commitment and turnover intentions. Journal of vocational behavior, 51(2), 319337.

Jawahar, I. M., \& Hemmasi, P. (2006). Perceived organizational support for women's advancement and turnover intentions: The mediating role of job and employer satisfaction. Women in Management Review, 21 (8), 643-661.

Kazimi, M., \& Nikkhah Farkhani, Z. (2008). The application of DEA in measuring and analyzing the relative performance of Khorasan Razavi Province's towns in sowing rained wheat. Quarterly Journal of Economics and Agricultural Development (Agricultural Sciences and Industries), 2(23), 87-94.

McDowall, A., \& Fletcher, C. (2004), Employee development: an organizational justice perspective. Journal of Personnel Review, 33(1), 829-841.

Mehregan, M. (2004). Assessing organizations' performance: A quantitative approach using DEA, Tehran, Tehran University Press.

Moini, A., Kazimi, M., \& Asgharpour, M. (2004), Determining an appropriate relation between inputs and outputs in Iran's electricity distribution companies. Journal of Knowledge and Development, (16) 104-122.

Mokhtar, A., Abdullah, N, \& Alhabshi , S. (2008), Efficiency and competition of Islamic banking in Malaysia. Journal of Humanomics, 24(1), 28-48.

Mulki, J. P., Jaramillo, F., \& Locander, W. B. (2006). Effects of ethical climate and supervisory trust on salesperson's job attitudes and intentions to quit.Journal of Personal Selling and Sales Management, 26(1), 20-26.

Narasimhan, R., \& Talluri, S. (2004). Exploring flexibility and execution competencies of manufacturing firms. Journal of Operations Management, 22, 91-106.

Posner, B., \& Schmidt, W. (1993). Value congruence and differences between the interplay of personal and organizational value systems. Journal of Business Ethics, 12, 126-146.

Ramanathan, R. (2007). Supplier selection problem: integrating DEA with the approaches of total cost of ownership and AHP. Supply Chain Management: An International Journal,12(2), 258-261.

Ramsey, R., Johnston, MW. Deeter-Schmelz, DR, \& Marshall, G. (2007). Ethical ideologies and older consumer perceptions of unethical sales tactics. Journal of Business Ethics, 57, 225-231.

Sarmad, Z., Bazargan, A., \& Hijazi, A. (2006), Methodologies in behavioral sciences, Tehran.

Sekaran U. (2002). Research methods for business. John Wiley \& Sons. 
Shields M.A, \& Ward M (2001). Improving nurse retention in the National Health Service in England: the impact of job satisfaction on intentions to quit. Journal of Health Economics, 20(5), 677-701.

Tanaomi, M. (1994), Quitting intentions and their realization. Journal of Management Knowledge, 21-50.

Wong, W. P., \& Wong, K. Y. (2007). Supply chain performance measurement system using DEA modeling. Industrial Management and Data Systems, 107(3), 361-381

Yao, S., Han, Z , \& Feng, G. (2007). On technical efficiency of China's insurance industry after WTO accession. China Economic Review, 18, 66-89. 